\title{
Cadmium-Containing Quantum Dots Used in
}

\section{Electronic Displays: Implications for Toxicity and}

\section{Environmental Transformations}

Aude Bechu ${ }^{\dagger}$, Jeffrey Liao ${ }^{\ddagger}$, Chang Huang ${ }^{\ddagger}$, Chany Ahn ${ }^{\dagger}$, Maureen McKeague ${ }^{\dagger *}$, Subhasis

Ghoshal $^{\dagger \S^{*}}$, Audrey Moores $\pm^{\#^{*}}$

${ }^{\dagger}$ Department of Chemistry, McGill University, Montreal, Quebec H3A 0B8, Canada

‡ Department of Pharmacology \& Therapeutics, McGill University, Montreal, Quebec H3G 1Y6, Canada

$\S^{\S}$ Department of Civil Engineering, McGill University, Montreal, Quebec H3A 0C3, Canada;

\pm Centre for Green Chemistry and Catalysis, Department of Chemistry, McGill University, Montreal, Quebec H3A 0B8, Canada

\#Department of Materials Engineering, McGill University, Montreal, Quebec H3A 0C5, Canada

KEYWORDS: Quantum Dots, Display, Environmental fate, Ion release, Liver cells, Toxicity

ABSTRACT: Cadmium-containing quantum dot nanoparticles (QDs) are integrated into electronic displays because of their ability to efficiently convert colors. There are conflicting accounts as to whether these particles present a hazard to the environment, as they have been 
studied either as (1) embedded QDs in display screen films or (2) as model QDs with small, hydrophilic ligands. Both approaches have limitations that we addressed by synthesizing QDs featuring the core-shell structure and the thick polymer coating present in commercial devices, to probe the dissolution of QDs in response to two environmental factors (pH, dissolved oxygen) over 1 day and 6 months. Results show that QDs were chemically stable at circumneutral $\mathrm{pH}(0 \%$ Cd dissolution after 6 months), but low pH initiated rapid dissolution under both aerobic and anaerobic conditions (up to $100 \%$ Cd dissolution after 6 months). In addition to the presence of a capping polymer, the QDs shell structure led to more chemically stable nanoparticles compared to non-shelled QDs, as the presence of ZnS shells decreased Cd dissolution by 75\%. The dense aggregation of QDs into structures of $\sim 100 \mathrm{~nm}$ in diameter over time was observed as well, which could lead to decreased bioavailability. To test this, we used liver cells to compare the toxicity of pristine QDs to those subjected to acid dissolution. Our results reveal that low-pH exposed QDs separated from dissolved ions are less toxic than pristine QDs (IC50 of 290 and $150 \mathrm{mg} / \mathrm{L}$, respectively) and suggest a key role of dissolved ions and capping polymers for QD toxicity. These findings highlight the use of a commercially-relevant nanoparticle structure to demonstrate fate and toxicity.

INTODUCTION: Quantum dots (QDs) are versatile nanoparticles whose excitons are confined in three dimensions, creating a distinct bandgap and narrow emission. ${ }^{1,2}$ With innovations in synthesis and measurement techniques, the quantum yield of certain QDs approaches unity. ${ }^{3}$ Such nanomaterials are used in electronic displays as they can enhance color, durability, and efficiency for both green and red pixels. ${ }^{4}$ High-performance electronic displays containing QDs have been available since 2013, with sales increasing every year. ${ }^{5}$ 
Commercial QDs are complex nanostructures containing several essential parts, important for both their function and their formulation, namely a core, a shell, a ligand, and possibly a capping polymer. The core is responsible for the desired optical properties and commonly made of a semiconductor. The wavelength of emitted light is dependent on the easily tunable QD core size. ${ }^{6}$ Cadmium selenide (CdSe) initially emerged as a preferable core material because of its emission in visible wavelengths and its simple synthesis that has cheap and air stable precursors. ${ }^{7,8}$ Although many materials are cited in patents as good for QD use in electronics, CdSe is highlighted because of "the relative maturity of the synthesis". ${ }^{9}$ These cores are then covered by an inorganic shell to shield them from oxidation and further increase quantum yield. ${ }^{10} \mathrm{CdSe}$ QD cores can be protected by layers, i.e., shells of CdS, ZnSe, ZnS, silica, or a combination of these materials which inhibit non-radiative recombination by providing distance between the core and possible surface defects. ${ }^{10,11}$ Next, these layers or shells are often stabilized by an organic ligand and/or a capping polymer. The organic ligand plays a role in the core and shell synthesis in order to control the size as well as optical properties and the capping polymer helps with QDs stability and formulation in a desired media (water, plastics precursors, organic solvents, etc.). ${ }^{12}$ In the case of commercial QDs for display applications, both a small molecule organic ligand and a capping polymer are used. ${ }^{9}$ The tunability and complexity of possible QD structures is a reason for their successful integration into electronics. But their varied and complex structures and proprietary synthesis protocols makes it difficult to accurately reproduce commercially-relevant QDs for academic purposes.

With only $20 \%$ of electronic waste properly recycled, ${ }^{13}$ QDs are likely to be released into the environment through either (1) leakages and discharges from engineered landfills or unregulated waste dumps to soil and groundwater, or (2) unregulated recycling in unsafe 
conditions. A significant number of displays manufactured have QD cores containing Cd, which is a known carcinogenic and bio-accumulative heavy metal, with recommended drinking water limits of $0.003 \mathrm{mg} / \mathrm{L} .{ }^{14}$ Therefore, the potential release of Cd through aged quantum dots is a concern. Ageing QDs - i.e. exposing them in a prolonged fashion to the environment or to specific environmental conditions (e.g. a range of $\mathrm{pH}$, dissolved oxygen, natural organic matter) in model systems $-{ }^{15}$ can lead to nanoparticle dissolution, aggregation, among other transformations. The ageing of QDs has been studied using either (1) model QD structures dispersed in aqueous solution and (2) commercial products within which proprietary complex QD-containing structures are embedded.

Model QDs (1) are commonly CdSe cores with ZnS shells which are designed to be initially colloidally stable, are easily tracked (through fluorescence or isotopes present) and usually contain either small molecules as ligands, or innocuous polymers used for toxicity tests. ${ }^{16-18}$ The study of (1) model QDs suggests a high potential for rapid dissolution in response to low or high $\mathrm{pH}$. For example, Paydary et al. noted that $\mathrm{Cd}$ and $\mathrm{Zn}$ dissolution at $\mathrm{pH} 7$ reached equilibrium after either 8 days (Zn) or 80 days (Cd) from CdSe/ZnS-mercaptopropionic acid QDs. ${ }^{16}$ Lowering the $\mathrm{pH}$ to 4 increased those rates. ${ }^{16}$ Mahendra et al. demonstrated a $100 \times$ increase in soluble Cd and Se from CdSe/ZnS (with unknown polymer ligand) QDs at $\mathrm{pH}$ of 2 and 12 compared to $\mathrm{pH} 7$ after only 30 min. ${ }^{19}$ These studies do not decouple the roles of low $\mathrm{pH}$ and oxygen, both of which could be key to initiating the dissolution of sulfides and selenides. Aggregation is another alternative fate of QDs under environmentally representative conditions. The stable hydrodynamic radius of polymer-coated CdSe/ZnS QDs in seawater has been noted ${ }^{20}$ and increased concentration of solutions spurred aggregation (at $20 \mathrm{ppm}$ CdSe/ZnS-mercaptopropionic acid QDs). ${ }^{16}$ Different ligands, thioglycolic acid and poly(maleic anhydride-alt-1-octadecene), initiated different amounts 
of aggregation and dissolution in soil column experiments. ${ }^{21}$ However, the model QDs used in such fate studies are often coated with ligands selected for their ability to disperse QDs in water, for use as innocuous biosensors or in other medical applications, or as a benign coating for toxicity tests. Their structure greatly differ from the ones of QDs in real devices, which are designed for formulation and long-lasting fluorescence when incorporated into a product, usually through encapsulation into a polymer. ${ }^{9}$ These proprietary QDs are therefore designed with different shell structures, ligands and capping polymers than previously studied model QDs, which may directly impact both their stability and toxicity.

In contrast, other groups have decided to study QDs already embedded in products (2) and in these cases have found that the particles are relatively chemically stable. For example, a study on QD-containing polymer prototype for LEDs (QD Vision) indicated that, after 30 days, 7\% Cd leaching under near-neutral conditions ( $\mathrm{pH} 5$ or $1 \mathrm{mM} \mathrm{H}_{2} \mathrm{O}_{2}$ ). ${ }^{22}$ A QD-containing Kindle (Amazon) film leached only $10 \%$ of its Cd after the waste extraction test (WET) using citric acid at $\mathrm{pH} 5 .{ }^{23}$ However, these studies provide limited information on how QDs are transformed because they assess an entire product, in which QDs cannot be separated from the encapsulating solid matrix and do not allow for extraction of QD materials necessary for in-depth characterization and fate analysis. Additionally, limited effort was devoted to low pH exposures, despite their environmental and biological relevance. Furthermore, the impacts of certain environmental conditions on QD transformations could be suppressed. For example, the dissolution of QDs could be altered by the absorption of ions on another component of the product (e.g., the encapsulating solid matrix).

In addition to the dissolution of QDs in the environment, it is necessary to determine the toxicity trends associated with commercially-relevant QDs and how the toxicity changes with environmental ageing. When comparing different pristine Cd-containing QDs, it has been reported 
that toxicity is mediated by surface components (i.e. ligand and metal sulfide shell), ${ }^{24}$ but such surface components change after particle ageing. Several studies have demonstrated that certain model QDs become more toxic as they age. ${ }^{18,19}$ As an example, CdSe/ZnS QDs capped with polyethylene glycol transformed into $\mathrm{Cd}$ ion and Se nanoparticles after exposure to oxidative conditions, resulting in increased toxicity to zebrafish embryos ( $\mathrm{LC}_{50}$ of $50 \mu \mathrm{M}$ Cd equivalents prior to oxidative conditions versus $10 \mu \mathrm{M}$ Cd equivalents after exposure). ${ }^{18}$ The exposure of QDs to non-physiological $\mathrm{pH}$ increased toxicity as well, but the toxicity of constituent ions dosed together could not explain the aged QD toxicity increase to bacteria. ${ }^{16}$ These studies lay an important and extensive groundwork for the toxicity study of aged QDs, but certain aspects of these QDs studies hinder the prediction of toxicity of QDs in electronics. In short, aged QD toxicity studies suffer from a similar constraint as QDs transformed by the environment: the studied QD does not model the complexities of QDs used in products. In addition, they do not address the possible toxicity of aged QDs alone, separate from their ionic constituents

As toxicity is closely linked to both QD surface coating and QD ageing, the gap between the environmentally-mediated transformation of model particles and QD-containing products must be addressed. There is a disconnect between the high dissolution of uncoated or simplified composition model QDs compared to the low release of ions from QD-containing products. This contradiction merits the use of better QD models that are representative of the more chemically stable QDs in products, both for ageing and subsequent toxicity studies. The assessment of the combination of environmental aging and subsequent toxicity of a QD model that is relevant to the industry is an innovative approach to the assessment of possible end-of-life nanoparticle hazard.

To bridge the gap, we synthesized a representative commercial QD, and assessed it dissolution, aggregation, and toxicity in aqueous media. While it is unknown to what extent 
commercially relevant QDs released from disposed products in landfills or during recycling would compare to the pristine forms of those QDs added into products, the assessment of the environmental transformations and toxicity of the pristine QDs could serve as a 'worst case' scenario. We synthesized and used the 'most preferable' capping polymer ${ }^{9}$ mentioned in the patent outlining QDs for display use. To further mimic conditions in display screens, we used an excess of this capping polymer compared to QDs. We examined the effect of exposing QDs to two environmental factors: $\mathrm{pH}$ and dissolved oxygen with short (1 day) and long term (6 months) ageing. The impact of $\mathrm{pH}$ on the chemical stability of the different shells and the core that constitute the commercially relevant QDs were assessed. We then compared the toxicity of a commercial model of pristine QDs and aged QDs in a human cell line. Furthermore, we examined QD cytotoxicity on a common model for the liver, HepG2 cells, to specifically address the impact of commercially-relevant ligands on fate and toxicity. This study brings attention to the importance of the role of an abundant, relevant ligand designed for use in displays. This approach considers a chemist's interest in nanoparticle design, an environmental engineers' assessment of important natural ageing triggers, and a toxicologist's rigor in assessing the different parts of this complex nanoparticle. Given that these QDs that could be released into the environment, the knowledge of relevant transformation reactions and toxicity trends can ultimately inform the design and assessment of safer QDs in the future.

\section{RESULTS AND DISCUSSION:}

\section{CdSe/ZnS-PEI\&E3P synthesis:}

Following our goal to access QDs that are relevant to QD in existing devices, we designed them according to the Quantum Dot Emission Film (QDEF) patent. ${ }^{9}$ This patent is assigned to Nanosys 
Inc, a major manufacturer in the QD display industry. Both cadmium and zinc have been found in QD-containing display films in previous studies and we confirmed the presence of both of these elements in a QD display film (see Fig. S1). ${ }^{23}$ While the patent was not explicit on the QD core/shell synthesis, it did mention that CdSe was an exemplary material for QDs, preferably with the presence of both CdS and ZnS shells. ${ }^{9}$ We hypothesize that these QDs possess a cadmium selenide (CdSe) core for narrow emission, an alloyed cadmium sulfide zinc sulfide (CdS/ZnS) shell for enhancement of quantum yield and stability. ${ }^{25}$ The QDs are capped by a polymer, i.e. polyethyleneimine reacted with an epoxide (PEI\&E3P), also mentioned by the patent. ${ }^{9}$ We confirmed the presence of key functional groups of PEI\&E3P in QD-containing films extracted from a commercial display using ${ }^{13} \mathrm{C}$ solid state carbon nuclear magnetic resonance $\left({ }^{13} \mathrm{C}\right.$-ssNMR, see Fig. S2). With this information, we designed a synthesis for CdSe//ZnS-PEI\&E3P QDs (see Scheme 1).

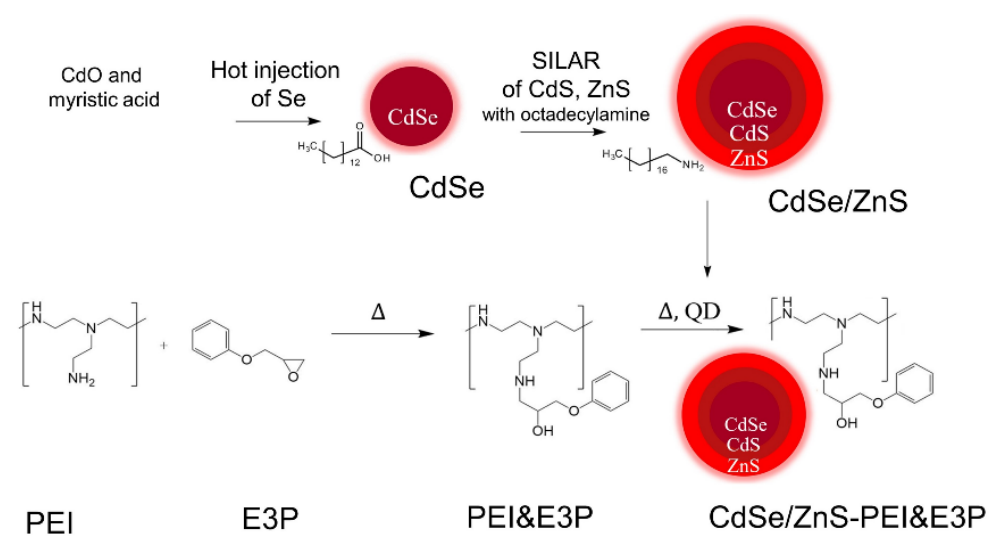

Scheme 1: Outline of CdSe/ZnS-PEI\&E3P synthesis. The process begins with the hot-injection synthesis of CdSe QDs, followed by the addition of alloyed CdS/ZnS shells using the SILAR method (alloyed shells from 3 subsequent precursor additions without purification; $\left.\mathrm{CdS} / \mathrm{Cd}_{0.5} \mathrm{Zn}_{0.5} \mathrm{~S} / \mathrm{ZnS}\right)$. On the bottom left is the reaction between polyethyleneimine (PEI) and 1,2 epoxy-3-phenoxypropane (E3P) to yield the product of PEI\&E3P. CdSe/ZnS QDs were then 
integrated into the PEI\&E3P. This procedure is adapted from a patent outlining the use of QDs in display applications. ${ }^{9}$

Because no specific core/shell synthesis was mentioned in the patent, we chose to synthesize a CdSe core QD with a graded shell of CdS/ZnS based on a previously published synthesis. ${ }^{26,27}$ Specifically, myristic acid stabilized CdSe nanoparticles were synthesized as cores. ${ }^{26}$ The emission peak of the cores was $595 \mathrm{~nm}$ with a full width at half max (FWHM) of $34 \mathrm{~nm}$ (see Fig. S3, Table S1). The transmission electron microscopy (TEM) analysis of these spherical particles indicated that their average diameter was $3.2 \pm 0.4 \mathrm{~nm}$ ( $\mathrm{n}=50$, Fig. S4). These particles were also crystalline, as demonstrated by lattice lines on the TEM and peaks on powder X-Ray diffraction (pXRD, Fig. S5).

Next, inorganic shells were added onto the core using successive ion layer absorption and reaction (SILAR) method that uses octadecylamine as a ligand. ${ }^{27}$ We chose to add 3 different layers to the shell, from CdS to $\mathrm{Cd}_{0.5} \mathrm{Zn}_{0.5} \mathrm{~S}$, to $\mathrm{ZnS}$ for all QDs because this procedure has proven to decrease the lattice mismatch between shells and enhance photostability. ${ }^{25}$ These shells were added sequentially to the reaction mixture (i.e. no purification between their additions). There was a 10 minute gap between additions of the shell elements (either $\mathrm{Cd}, \mathrm{Cd}_{0.5} \mathrm{Zn}_{0.5}, \mathrm{Zn}$, or S), which had been previously established because after this time period the optical properties displayed no further changes. ${ }^{27}$ These inorganic sulfide shells will be referred to as "alloyed" shells. QD particles increased in diameter from $3.2 \pm 0.4 \mathrm{~nm}$ (cores) to $4.8 \pm 0.8 \mathrm{~nm}$ when the shells were added (Figure 1A). The shape variation of the shelled QDs indicates that the addition of different layers to (i.e. shelling) the spherical core is not completely uniform. However, these size ranges and shapes align with those previously reported in the literature for the shelling of synthesized and purchased quantum dots. ${ }^{27,28,16,29}$ The crystallinity of the samples is observed via pXRD 
measurements, which indicate a cubic structure of CdSe core, CdS, and ZnS alloyed shells present in the QDs (Figure 1B). Three reflections of the cubic phase are indicated in the figure, where broad peaks are a result of the mix of CdS, ZnS and CdSe present. ${ }^{30,31}$ Both TEM and pXRD spectra were taken without the addition of the capping polymer (see procedure below) because the large quantity of organic molecules in that polymer could obscure the bulk and particulate crystallinity observations. The addition of alloyed shells, CdS to $\mathrm{Cd}_{0.5} \mathrm{Zn}_{0.5} \mathrm{~S}$, to $\mathrm{ZnS}$ (with each layer added sequentially without purification in between), for all CdSe QDs, is key to designing stable, commercially relevant QDs. This alloyed shell structure is important to keep in mind as these particles are aged later in the paper.
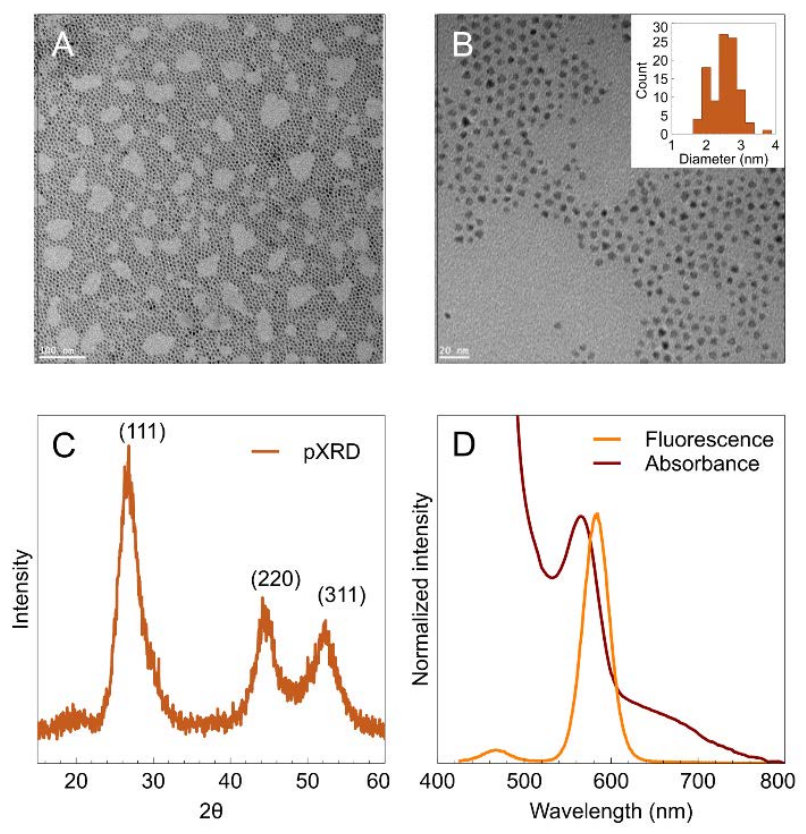

Figure 1: (A,B) Representative TEM image of CdSe/ZnS-octadecylamine QDs with inset demonstrating size range of CdSe/ZnS QDs by TEM (n=200) (C) pXRD CdSe/ZnSoctadecylamine QDs and (D) Absorbance (red) and fluorescence (orange) of CdSe/ZnS PEI\&E3P in toluene (excitation at $400 \mathrm{~nm}$ ). 
After the addition of inorganic shells to the CdSe core, the ligand present on the surface of these QDs is octadecylamine because of the synthesis. We then coated these QDs in an additional capping polymer layer. ${ }^{9}$ Polyethyleneimine (PEI) and 1,2-epoxy-3-phenoxypropane (E3P) were combined under argon in an addition reaction which formed a C-N bond (see Scheme 1). The synthesized polymer was characterized by ${ }^{1} \mathrm{H}-\mathrm{NMR}$ (see Fig. S6). The characteristic sharp peaks of the epoxide at $4.25,3.95$, and $2.92 \mathrm{ppm}$ broadened and shifted as they were incorporated in the broad peak of the polymer network from 2.4 to $2.8 \mathrm{ppm}$ and 3.8 to $4.2 \mathrm{ppm}$ (Fig. S6). Importantly, the hydrogen directly bonded to the secondary carbon on the epoxide ring in E3P at $3.38 \mathrm{ppm}$ is no longer apparent, indicating that no epoxide rings could react with QDs (Scheme 1).

In Scheme 1, QDs were added to the as-synthesized capping polymer at $100^{\circ} \mathrm{C}$. To ensure that the same amount of QD was added to this polymer in each synthesis, thermogravimetric analysis (TGA) was done on every CdSe/ZnS-octadecylamine sample to evaluate the ratio of inorganic/organic contents (Fig. S7). The organic content (octadecylamine) varied from 30-40\% depending on the QD sample. With the ratio known for each sample, the amount of QDs added to the $450 \mathrm{mg}$ of the polymer was adjusted so that the total inorganic weight added for every synthesis would be the same (20 mg). These synthesized QDs were labeled as CdSe/ZnS-PEI\&E3P, which were approximately $4 \mathrm{wt} \%$ inorganic QD. This translates to $2 \mathrm{wt} \% \mathrm{Cd}$ and $1 \mathrm{wt} \% \mathrm{Zn}$, which was later confirmed via acid/ $\mathrm{H}_{2} \mathrm{O}_{2}$ digestion and measurement in the ICP-OES. This low amount of QD reflects the amounts of QDs used in the QD film in display applications, which is approximately $0.01 \%$ Cd. ${ }^{32}$

After the addition of a capping polymer, we checked that the desired QD properties were still intact. The preservation of the QD fluorescence was demonstrated by the preserved emission of the QDs at $584 \mathrm{~nm}$ with a full width at half max (FWHM) of $34 \mathrm{~nm}$ (Figure 1D, Table S1). This 
correlates well to the fluorescence of the CdSe core (peak emission of $595 \mathrm{~nm}$ and FWHM of 37 $\mathrm{nm})$. The fluorescence changes with coating of ZnS-PEI\&E3P represent a slight decrease in core size, but a slight increase in core uniformity. ${ }^{33}$ The ${ }^{1} \mathrm{H}-\mathrm{NMR}$ analysis also revealed octadecylamine ligands were still present (1-2 ppm peaks, Fig. S8).

In short, this construction of CdSe/ZnS-PEI\&E3P is focused on replicating the QDs found in displays (alloyed shell and polymer coating) while also maintaining the ability to fully synthesize and characterize a nanoparticle free of a plastic coating.

\section{CdSe/ZnS-PEI\&E3P dissolution in response to $\mathrm{pH}$ and oxygen:}

After the CdSe/ZnS-PEI\&E3P was synthesized, it was subject to dissolution tests to determine the amount of solubilized ions after exposure to $\mathrm{pH} 2-8$ as well as atmospheric $\mathrm{O}_{2}$ and anoxic $\left(\mathrm{N}_{2}\right.$ atmosphere) system (Figure 2). Initial sample preparation involved a pH adjustment with acetic acid because the solution of $100 \mathrm{mg} / \mathrm{L}$ of CdSe/ZnS-PEI\&E3P had an initial $\mathrm{pH}$ of 10 . We chose acetic acid because of its use in the Toxicity Characteristic Leaching Procedure ${ }^{34}$ to measure metal release from waste and because acetic acid prompted more dissolution of QDs from LDPE (compared to hydrochloric acid and citric acid) in a study by Duncan et al. ${ }^{35}$

The initial Cd and Zn concentrations in these dissolution tests were 3 and $1.5 \mathrm{mg} / \mathrm{L}$, respectively, all in nanoparticle form. After the exposure tests to specific environmental conditions were completed (dark conditions for either $24 \mathrm{~h}$ or 6 months), we separated the fraction of the sample containing $<3 \mathrm{kDa}$ species from any remaining nanoparticle matter ( $>3 \mathrm{kDa}$ ) using filtration with ultracentrifugation filters (see SI for method validation). Solubilized ion and nanoparticle fractions were digested separately with both nitric acid and hydrogen peroxide to release all metals present into solution and break down PEI\&E3P. ${ }^{36}$ Finally, the concentrations of $\mathrm{Zn}$ and $\mathrm{Cd}$ in the dissolved and nanoparticle solutions were measured using inductively-coupled plasma optical emission 
spectroscopy (ICP-OES). The results of the dissolution are presented as a percentage of the total metal content in the QDs which was found dissolved, i.e. which passed through a 3KDa filter. Specifically, $100 \%$ indicates that all metal was dissolved and none remained as components of a QD. These results in aerobic conditions (Figure 2A and 2B) were then compared to anaerobic conditions (Figure 2C and 2D).

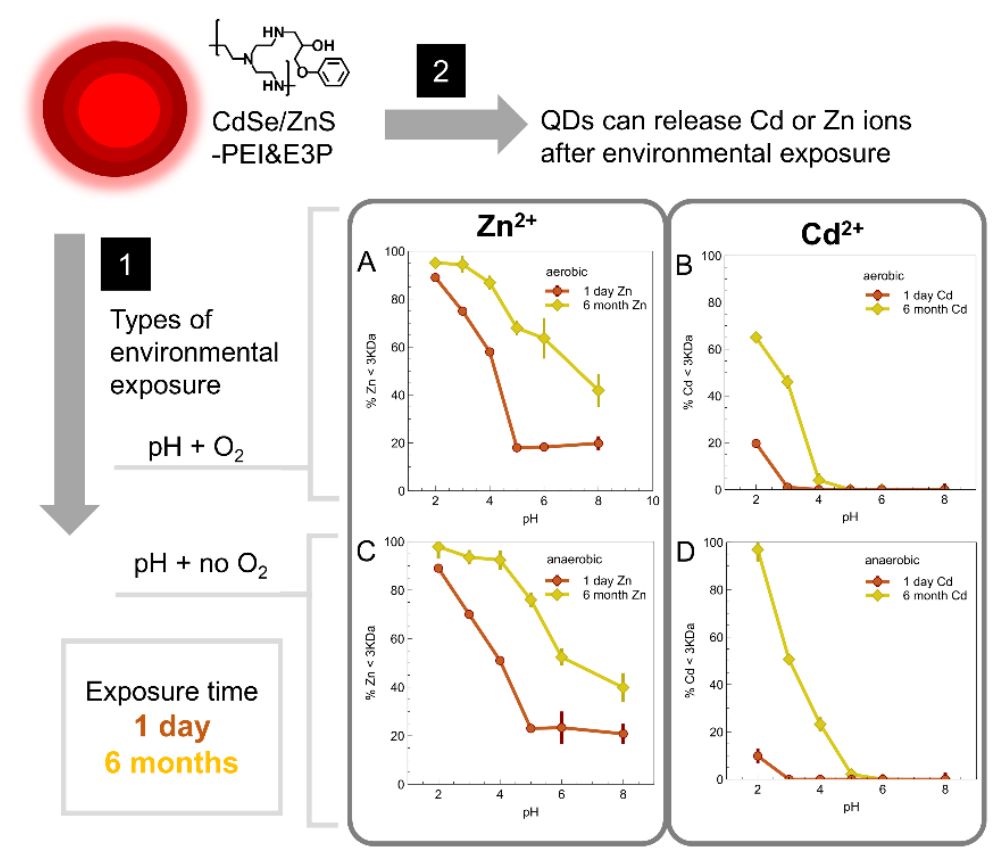

Figure 2: Dissolution of (A) Zn and (B) Cd after exposure to waters at varying $\mathrm{pH}$ for 1 day (orange circles) and 6 months (yellow diamonds) in a dark aerobic environment. (C) Zn and (D) Cd dissolution under an anaerobic environment kept all other conditions the same. Error bars represent the standard deviation of duplicate samples, each of which yielded three ICP-OES measurements (total six values used for each data point). 
This analysis of CdSe/ZnS-PEI\&E3P QDs ageing at $\mathrm{pH}$ 2-8 indicated that the free ion concentrations increased as $\mathrm{pH}$ decreased under both aerobic and anaerobic conditions. The $\mathrm{Zn}$ content of the QDs was almost completely dissolved as $\mathrm{Zn}^{2+}{ }_{(\text {aq) }}$ after 1 day at $\mathrm{pH} 2$, while only 5$10 \%$ of their Cd content was present as aqueous ions under the same conditions. After 6 months, the dissolution of $\mathrm{Zn}$ was complete for pHs below 4, while at pHs above $4 \mathrm{Zn}$ remained partially undissolved with the QD shells. Even after 6 months at pHs above 4, Cd overall remained undissolved. Only at pH 2 did we observe modest dissolution of Cd.

This lack of dissolution at circumneutral $\mathrm{pH}$ is in agreement with studies on QDs embedded in plastics or display films, but differs from results with model QDs. This result offers a validation of our synthetic design, in the sense that it affords a fully characterized model of a slow metals release particle, similar to the real ones found in devices. The CdSe/ZnS-PEI\&E3P QDs in this study released fewer metal ions than comparable CdSe/ZnS -mercaptopropionic acid QDs from another study at lower concentrations (1 ppm QD) under similar conditions (dark, circa 1 day dissolution time). ${ }^{14}$ After $24 \mathrm{~h}$ at $\mathrm{pH}$ 7, CdSe/ZnS-mercaptopropionic acid QDs released 30\% of their Cd and $90 \%$ of their $\mathrm{Zn},{ }^{14}$ while in this work CdSe/ZnS-PEI\&E3P released $0 \%$ of their Cd and $20 \%$ of their $\mathrm{Zn}$.

Ligand functional groups and their quantity may play a role in this limited dissolution. ${ }^{16,37}$ In fact, it is not common to report the amount of ligand or capping polymer used for dissolution tests. ${ }^{19,20,38}$ In this study, the amount of capping polymer may have influenced the robustness QDs at circumneutral pHs such that our model behaves more like QDs in displays.

Our studies indicated a significant difference in aerobic vs anaerobic conditions occurred after 6 months at pH 2 for Cd, where roughly 65\% of Cd was dissolved in aerobic conditions, but 100\% was dissolved in anaerobic conditions. In addition, the $\mathrm{pH}$ range for $\mathrm{Cd}$ dissolution increased from 
pH 2 in aerobic conditions to $\mathrm{pH}$ 2-4 in anaerobic waters. For Zn dissolution, aerobic conditions caused higher dissolution for $\mathrm{pH}$ 3-4 after 1 day compared to anaerobic conditions, but after 6 months there was no significant difference between in aerobic vs anaerobic conditions for $\mathrm{Zn}$ dissolution of all $\mathrm{pH}$ studied ( $\mathrm{p}<0.02$ is significance benchmark for all comparisons).

The two variations of conditions were chosen in order to decipher the role of oxygen in low $\mathrm{pH}$ metal sulfides (MS) dissolution experiments $\mathrm{pH}$. This dissolution reaction has been proposed before to proceed via either an anaerobic pathway (eq.1) or an aerobic one (eq. 2). ${ }^{39}$

$$
\begin{aligned}
& M S_{(s)}+2 H_{(a q)}^{+} \rightarrow H_{2} S_{(a q)}+M_{(a q)}^{2+}
\end{aligned}
$$

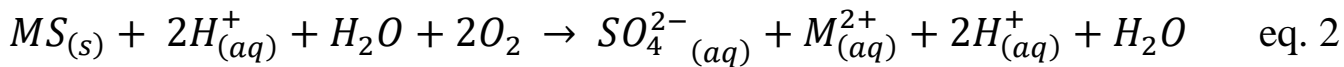

Eq. 1 describes a well-known mechanism for the dissolution of acid-soluble metal sulfides. ${ }^{40} \mathrm{In}$ Eq. 2, oxygen plays a role in further oxidizing sulfur-containing reaction by-products, but it may also participate in the dissolution itself, via sorption of $\mathrm{O}_{2}(\mathrm{aq})$ onto a metal sulfide so as to release sulfates and metal ions from the QD surface. ${ }^{29,39} \mathrm{Eq} 2$ may also proceed in another manner: Eq 1 followed by the oxidation of hydrogen sulfide to sulfate in solution. In this study, both aerobic and anaerobic dissolution rates for $\mathrm{ZnS}$ and $\mathrm{CdS}$ increased steadily as the $\mathrm{pH}$ was decreased, which is consistent with both equations 1 and 2 (Figure 2).

Yet, for Cd, the anaerobic conditions afforded faster dissolution than the aerobic ones, the difference being more pronounced after 6 months than 1 day. ${ }^{41}$ This point strongly suggests that indeed $\mathrm{O}_{2}$ must actively participate mechanistically to the aerobic dissolution of the metal sulfide itself so as to slow down the reaction in this case. For instance, the presence of $\mathrm{O}_{2}$ may trigger the formation of a passivating $\mathrm{CdO}$ layer locally. This explanation is consistent with the difference being more pronounced after a longer reaction time. 
To test whether the persistence of the CdSe/ZnS-PEI\&E3P in response to $\mathrm{pH}$ and oxygen was a result of the alloyed shell, we synthesized two other model particles. First, we synthesized ZnSPEI\&E3P to mimic the shell material (see SI for synthesis, Fig. S9 for characterization). ZnS particles were $4.0 \pm 0.6 \mathrm{~nm}(\mathrm{n}=100)$ in diameter capped with oleylamine because of the synthesis (compared to $4.8 \pm 0.8 \mathrm{~nm}$ diameter CdSe/ZnS synthesized with octadecylamine). Then, these ZnS QDs were stabilized by same capping polymer (PEI\&E3P) in the same procedure as CdSe/ZnS QDs. We measured the Zn ion dissolution from ZnS QDs at pH 2 and 4. The dissolution extent matched those of $\mathrm{Zn}$ in CdSe/ZnS QDs at pH 2 over 24h dissolution time, but at pH 4 there was less dissolution for ZnS compared to CdSe/ZnS QDs (Figure 3A). The fact ZnS dissolved preferably when it is shelled over CdSe than when it is the sole constituent of a nanoparticle can arise from the fact $\mathrm{ZnS}$ is likely to have more defects if it is grown over materials with different epitaxies (CdSe and CdS), as it has been shown by others. ${ }^{42}$ However, the difference between CdSe and ZnS is greater than that between CdS and ZnS. Therefore, the alloyed shells may decrease dissolution. This alloying is not mentioned in comparable QD dissolution studies with model QDs ${ }^{16}$ which may be a reason for their QDs relative lower stability.

Also, we synthesized CdSe-PEI\&E3P with no CdS or ZnS shells, with the same CdSe and PEI\&E3P methods used for CdSe/ZnS-PEI\&E3P. CdSe-PEI\&E3P QDs did not contain a long chain amine similar to CdSe/ZnS-PEI\&E3P and ZnS-PEI\&E3P, but instead myristic acid as a result of the synthesis. The dissolution of CdSe-PEI\&E3P after $24 \mathrm{~h}$ at $\mathrm{pH} 2$ and 4 is almost complete (>75\%, Figure 3B). Cd dissolution from CdSe-PEI\&E3P was much higher than in the sulfide-shelled CdSe/ZnS-PEI\&E3P, confirming the anticipated protective function of the shell in this context. 
Specifically, Cd ions can only be released from CdSe/ZnS-PEI\&E3P after complete dissolution of the ZnS shell, at which point the mixed Cd/Zn sulfide shell is exposed. After $24 \mathrm{~h}$, Cd dissolution at $\mathrm{pH} 2$ in aerobic conditions indicates that the $\mathrm{Cd}$ contained in this $\mathrm{Cd}_{0.5} \mathrm{Zn}_{0.5} \mathrm{~S}$ layer is partially dissolved ( $22 \%$ of all Cd, Figure 2B), however, the remaining CdSe core is intact. This protection of CdSe core however, is only temporary. The dissolution results for Cd after 6 months (60-100\% of $\mathrm{Cd}$ is dissolved at $\mathrm{pH}$ 2, Fig.1) points to the fact that CdSe and CdS are not stable in the long term under low $\mathrm{pH}$. This long-term outlook on the potential dissolution of CdSe/ZnS-PEI\&E3P is necessary to determine the possible results of QD dissolution.

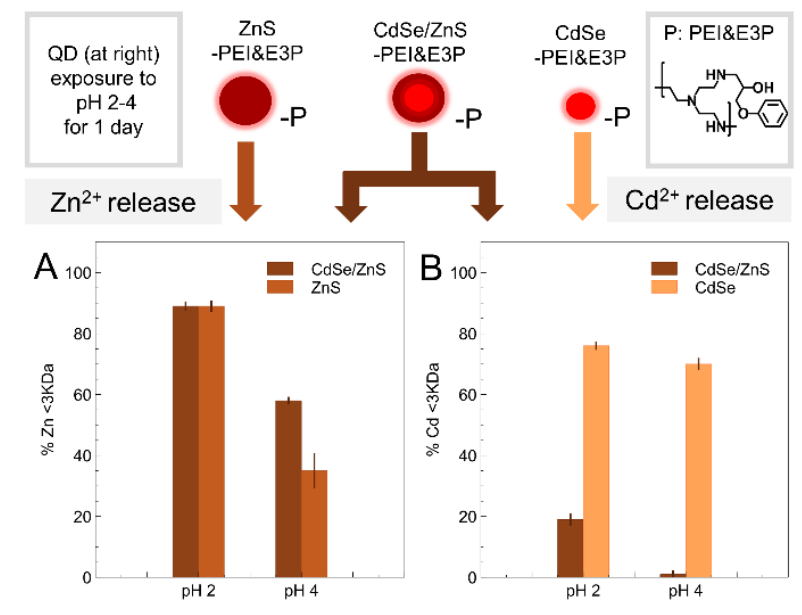

Figure 3: (A) Dissolution of Zn from CdSe/ZnS-PEI\&E3P and ZnS-PEI\&E3P and (B) dissolution of Cd from CdSe-PEI\&E3P and CdSe/ZnS-PEI\&E3P. Dissolution was measured after $24 \mathrm{~h}$ in the dark in aerobic conditions at $\mathrm{pH} 2$ and 4 regulated by acetic acid.

\section{Aggregation of CdSe/ZnS-PEI\&E3P}

Besides dissolution, CdSe/ZnS-PEI\&E3P particles may undergo transformations, namely their ability to aggregate. To gain insight into the structural evolution of these nanoparticles, we 
investigated them after different ageing events with dynamic light scattering (DLS) and $\zeta$-potential measurements. At $0.3 \mathrm{mg} / \mathrm{mL}$ at neutral $\mathrm{pH}$, the $\zeta$-potential of CdSe/ZnS-PEI\&E3P was on par with the $\zeta$-potential of PEI\&E3P alone at $+35-45 \mathrm{mV}$, which confirms the surface charge of CdSe/ZnS-PEI\&E3P are stemming entirely from their capping polymer. With decreasing $\mathrm{pH}$ to 8, the $\zeta$-potential decreases slightly (to $26-28 \mathrm{mV}$ ), indicating that the protonation extent of the capping polymer is only slightly decreased (Fig. S10). Over $\mathrm{pH} 2-8$, the hydrodynamic size of CdSe/ZnS-PEI\&E3P in solution after $1 \mathrm{~h}$ is slightly larger than polymer alone (hydrodynamic radius is stable at $100-130 \mathrm{~nm}$ over $\mathrm{pH} 3-9$ ). This large hydrodynamic size of the CdSe/ZnSPEI\&E3P was maintained after $24 \mathrm{~h}$ as well (Fig. S10). These hydrodynamic sizes and zeta potentials are relatively stable over the pHs measured, compared to CdSe/ZnS QDs coated with octylamine-modified poly(acrylic acid) ${ }^{43}$

The fluorescence of QDs has also been linked to the aggregation state of the particles. The fluorescence of CdSe/ZnS-PEI\&E3P was measured after 1 hour, 1 day, and three weeks (Fig. S11 and S12). After 1 day, fluorescence peak intensity from pH 6 and 8 decreased, while intensity at $\mathrm{pH} 4$ increased to $170 \%$ of initial intensity (taken after 1h). A similar increase in fluorescence intensity has been well documented for thiol-based ligands, ${ }^{44}$ but in this case amines may be temporarily passivating surface traps with protons. These spectra indicate that after 3 weeks, there is a complete loss of fluorescence of QDs in solution. This could partly be due to degradation of the QD structure, via shell dissolution at low pHs, or due to aggregation. Aggregation proved to be influential because the vortexing of solutions for $30 \mathrm{~min}$ increased the fluorescent signal intensity to 35\% of the initial fluorescence intensity. This technique indicated that QDs were aggregating over time. 
To gain more insight in the structure of nanoparticle aggregates, we performed a complementary study by TEM and EDS. CdSe/ZnS-PEI\&E3P was initially suspended at $\mathrm{pH} 4$ and drop cast onto a TEM grid (Figure 4A,B), demonstrating particles that are discrete and not stacked on one another. While TEM analysis does not allow direct visualization of ligand or capping polymer (or both) at the QDs surface, it is realistic to assume that these dispersed particles are initially stabilized by organics.

After ageing CdSe/ZnS-PEI\&E3P for 1 day in $\mathrm{pH}$ 4, we filtered the sample and retained the $>3 \mathrm{kDa}$ fraction (i.e. particles larger than $\sim 1.5 \mathrm{~nm}$ ). These QDs demonstrated larger loose aggregates than the QDs originally studied (Fig. 4C,D) indicating that the coating separating the QDs may be less effective at separating QDs over time. These structures are similar to those noted by Mukherjee et al, who demonstrated via TEM the loose aggregation of carboxyl- and aminecapped CdSe/ZnS (polymer unknown) in the presence of algal exudate. ${ }^{45}$

However, on the same TEM grids of $>3 \mathrm{KDa}$ fraction (i.e. particles larger than $\sim 1.5 \mathrm{~nm}$ ) after 6 months of ageing, we observed large tight aggregates of discrete nanoparticles (Figure 4E,F) that are of similar size and shape to the original QDs used for dissolution studies (Fig. 1A,B). Other studies have noted aggregation of hydrophobic QDs in response to increasing electrolyte concentration, humic acid presence, or oxidants as well. ${ }^{46-48}$ However, the tight aggregates reported here are smaller in size and induced solely with a long period of time and low $\mathrm{pH}$. Aggregation typically decreases the toxicity of nanoparticles, but a link between bioavailability and aggregation has not yet been established for such small QD aggregates with a commercially relevant capping polymer.

At all time frames, we found no evidence of reprecipitated species, which would have been particles of Cd or Zn-containing oxides or sulfides retained by the 3KDa filter. These reprecipitated 
species would have been either (1) a result or Cd or Zn ions in solution complexing with Se or S in solution forming crystals or amorphous solids or (2) elemental Se or S, such as those observed by Pedersen et $\mathrm{al}^{48}$ and Carrière et al. ${ }^{49}$ The stability of ions in our system could be due their chelation by amines in PEI\&E3P or simply due to a lack of other oxidizing or reducing species.

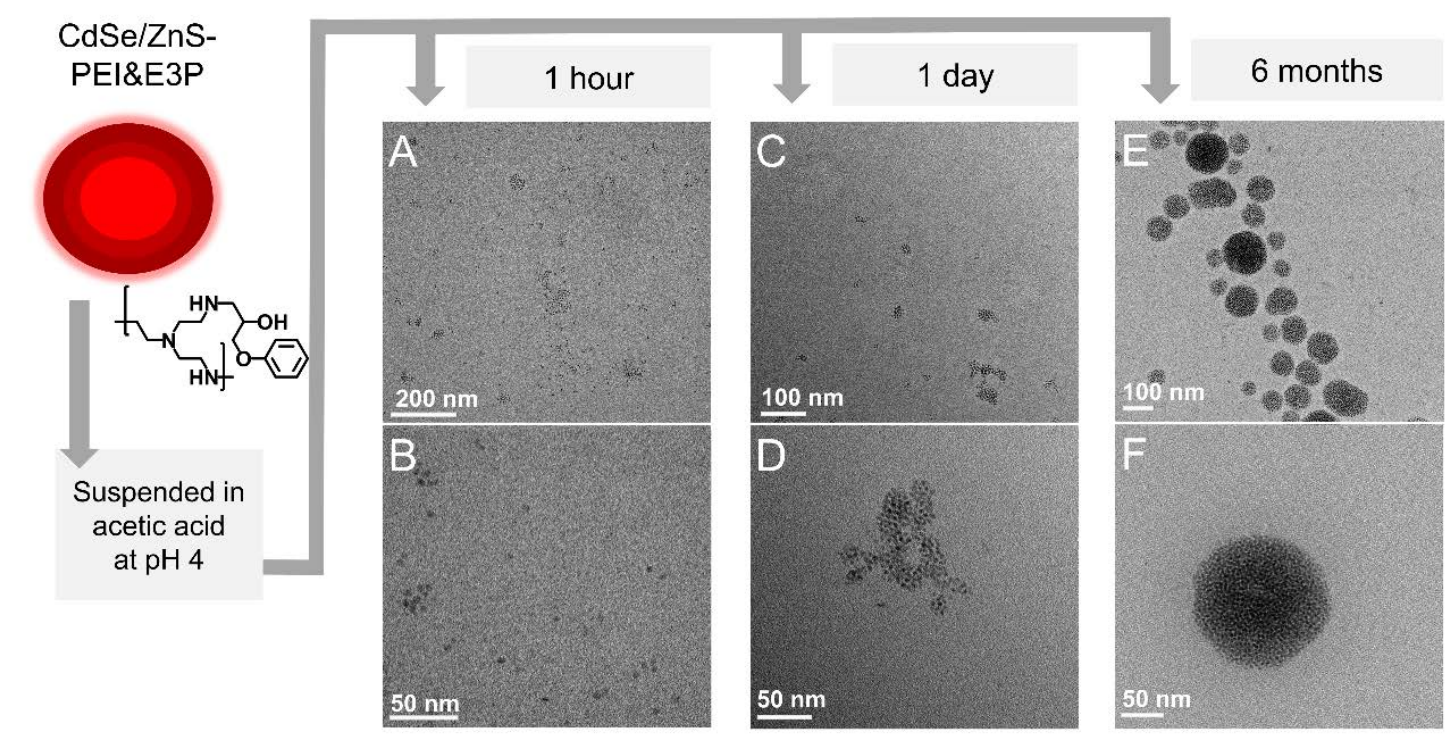

Figure 4: (A,B) TEM images of pristine CdSe/ZnS-PEI\&E3P and CdSe/ZnS-PEI\&E3P after 24h $(\mathrm{C}, \mathrm{D})$ and 6 months $(\mathrm{E}, \mathrm{F})$ of dissolution in aerobic conditions at $\mathrm{pH} 4$.

\section{Toxicity of CdSe/ZnS-PEI\&E3P to HepG2 Cells:}

From the fate experiments conducted above, we turned to toxicity measurements to better understand how sample ageing, and specifically the components emerging from it, are impacting the toxicity of the ensemble. We chose to use HepG2 liver cells because the number of metabolizing enzymes within hepatocytes makes the liver the primary susceptible organ to xenobiotics. ${ }^{50}$ 
We first validated a CellTiter-Glo Luminescence assay as a suitable cell viability assay for the HepG2 cell model by measuring cytotoxicity resulting from exposure to $\mathrm{Cd}^{2+}$ ions for 1 day, the component in Cd-containing QDs most commonly associated with toxicity. ${ }^{51}$ The impact of $\mathrm{Cd}^{2+}$ on HepG2 cell viability has been intensively studied $\left(\mathrm{IC}_{50}=1.7 \mathrm{mg} / \mathrm{L}^{52}\right.$ and $\left.\mathrm{IC}_{50}=1.1 \mathrm{mg} / \mathrm{L}^{53}\right)$, and we observed a similarly high sensitivity of HepG2 cells. Toxicity was independent of counter ions present $\left(\mathrm{CdCl}_{2} \mathrm{IC}_{50}=0.64 \pm 0.08 \mathrm{mg} / \mathrm{L}\right.$ and $\mathrm{Cd}\left(\mathrm{NO}_{3}\right)_{2} \mathrm{IC}_{50}=0.5 \pm 0.2 \mathrm{mg} / \mathrm{L}$; detailed results Fig. S13).

Having validated the luminescence assay, we next determined cytotoxicity resulting from other components in CdSe/ZnS-PEI\&E3P including $\mathrm{Zn}^{2+}$ and the PEI\&E3P ligand. Our results confirm that $\mathrm{Zn}^{2+}$ is much less toxic than $\mathrm{Cd}^{2+}$, independent of the counter ion $\left(\mathrm{ZnSO}_{4} \mathrm{IC}_{50}=30 \pm 12 \mathrm{mg} / \mathrm{L}\right.$ and $\left.\mathrm{Zn}(\mathrm{OAc})_{2} \mathrm{IC}_{50}=26 \pm 7 \mathrm{mg} / \mathrm{L}\right)$ : viability results in Fig. S14. Our results are in line with previous experiments in zebrafish Danio rerio liver cells after a 24h incubation period $\left(\mathrm{ZnSO}_{4} \mathrm{IC}_{50}=67\right.$ $\mathrm{mg} / \mathrm{L}){ }^{54}$ In contrast, PEI\&E3P has not been previously tested in terms of toxicity on HepG2 cells. PEI\&E3P ligand however, while not as toxic as $\mathrm{Cd}^{2+}$ to HepG2 cells, featured significant toxicity with a measured $\mathrm{IC}_{50}$ value of $220 \pm 50 \mathrm{mg} / \mathrm{L}$ (viability results in Fig. S15). This toxicity of PEI\&E3P is particularly relevant considering the high ratio of this ligand present in QDs compared to $\mathrm{Cd}^{2+}$ and $\mathrm{Zn}^{2+}$ (i.e. $\mathrm{Cd}^{2+}: \mathrm{Zn}^{2+}$ : PEI\&E3P which is 2:1:100).

A rough comparison of PEI\&E3P to polyethylene glycol (PEG) capped TiO2 NPs ${ }^{55}$ (analyzed with the same cells and assays used here) indicates that PEI\&E3P is more toxic than PEG. When QDs capped with PEI are compared to QDs capped with negatively-charged or neutral ligands, the PEI-capped QDs are consistently more toxic. ${ }^{56,57}$ Although the hydrodynamic radius is reported in these studies, there is no clear indication of the mass of capping polymer used for those toxicity 
tests. Just as in environmental fate studies, reporting the mass of ligand used in toxicity tests is crucial.

We determined the toxicity of pristine CdSe/ZnS-PEI\&E3P (IC50 = $150 \pm 20 \mathrm{mg} / \mathrm{L}$, Fig. S16). Additionally, we confirmed the presence of QDs inside or strongly adhered to cells by washing the QD-exposed cells with fresh PBS and then observing the cells with confocal microscopy (Fig. S17). Despite clear interactions between the QDs and cell, QD-induced toxicity is difficult to compare to previous literature. Molarity of QDs is difficult to replicate between studies, ${ }^{51}$ and in this case molarity of QDs is skewed by the presence of a capping polymer (which makes up 96wt\%). Comparisons based on molarity of QDs alone would indicate that CdSe/ZnS-PEI\&E3P $(\mathrm{IC50}=90 \pm 10 \mathrm{nM})$ are much more toxic than previously studied CdSe/ZnS-PEG exposed to HepG2 cells (no cell toxicity observed at $100 \mathrm{nM}){ }^{58}$

\section{Exposing CdSe/ZnS-PEI\&E3P to low $\mathrm{pH}$ reduces the toxicity of the residual QD particles}

We next applied the same $24 \mathrm{~h}$ incubation viability assay to study how the toxicity changes following one case of environmentally-mimicked ageing (in this case $24 \mathrm{~h}$ at $\mathrm{pH}=2$ in aerobic conditions). We chose to study CdSe/ZnS-PEI\&E3P aged at $\mathrm{pH} 2$ for $24 \mathrm{~h}$ in aerobic conditions because this condition offered complete dissolution of the ZnS shell and partial dissolution of the CdS shells. However, to both mimic the ageing conditions in Figure 2 and allow for the calculation of $\mathrm{IC}_{50}$, samples were concentrated with ultrafiltration with $3 \mathrm{KDa}$ filters. Additionally, this concentration procedure reduces the acetic acid present and the amount of sodium hydroxide needed to neutralize it, while preserving the polymer concentration (Fig. S18).

We developed three model systems to specifically distinguish toxicity arising from the aged particles and the released ions (Figure 5A). These models include: 1) aged CdSe/ZnS-PEI\&E3P 
which were filtered (3 kDa) from the solution in which they were aged (called aged QDs alone) thus removing all dissolved $\mathrm{Cd}^{2+}$ and $\mathrm{Zn}^{2+}(20 \%$ of $\mathrm{Cd}$ in pristine QD and $100 \%$ of initial $\mathrm{Zn}$ in pristine QD) and neutralized with sodium hydroxide.; 2) concentrations of freshly prepared PEI\&E3P, $\mathrm{Cd}^{2+}$ and $\mathrm{Zn}^{2+}$ equivalent to what is measured in solution following ageing of $2 \mathrm{~g} / \mathrm{L}$ of CdSe/ZnS-PEI\&E3P (called ions and ligands); 3) the full model of aged CdSe/ZnS-PEI\&E3P, consisting of the aged QDs with $\mathrm{Cd}^{2+}$ and $\mathrm{Zn}^{2+}$ in solution due to ageing along with the remaining weathered particles themselves (Fig. S16-21, Table S2).

Our results confirm that the aged CdSe/ZnS-PEI\&E3P, after removing dissolved ions (20\% of total Cd and $100 \%$ of Zn), are significantly less toxic than pristine CdSe/ZnS-PEI\&E3P (aged IC50 $=290 \pm 60 \mathrm{mg} / \mathrm{L}$ vs pristine $\mathrm{IC}_{50}=150 \pm 20 \mathrm{mg} / \mathrm{L} ; \mathrm{p}=0.005$, Figure 5). Interestingly, there is no significant difference in comparing the toxicity of the fully aged CdSe/ZnS-PEI\&E3P model as well the model containing the relevant concentrations of dissolved $\mathrm{Cd}^{2+}, \mathrm{Zn}^{2+}$, and PEI\&E3P arising from weathering of the pristine QDs (Cd, Zn, PEI\&E3P model IC $50=170 \pm 30 \mathrm{mg} / \mathrm{L}$; fully aged QD model $\mathrm{IC}_{50}=190 \pm 40 \mathrm{mg} / \mathrm{L}$, Figure 5). This suggests that dissolved ions from QDs are the major source of toxicity to human cells. 


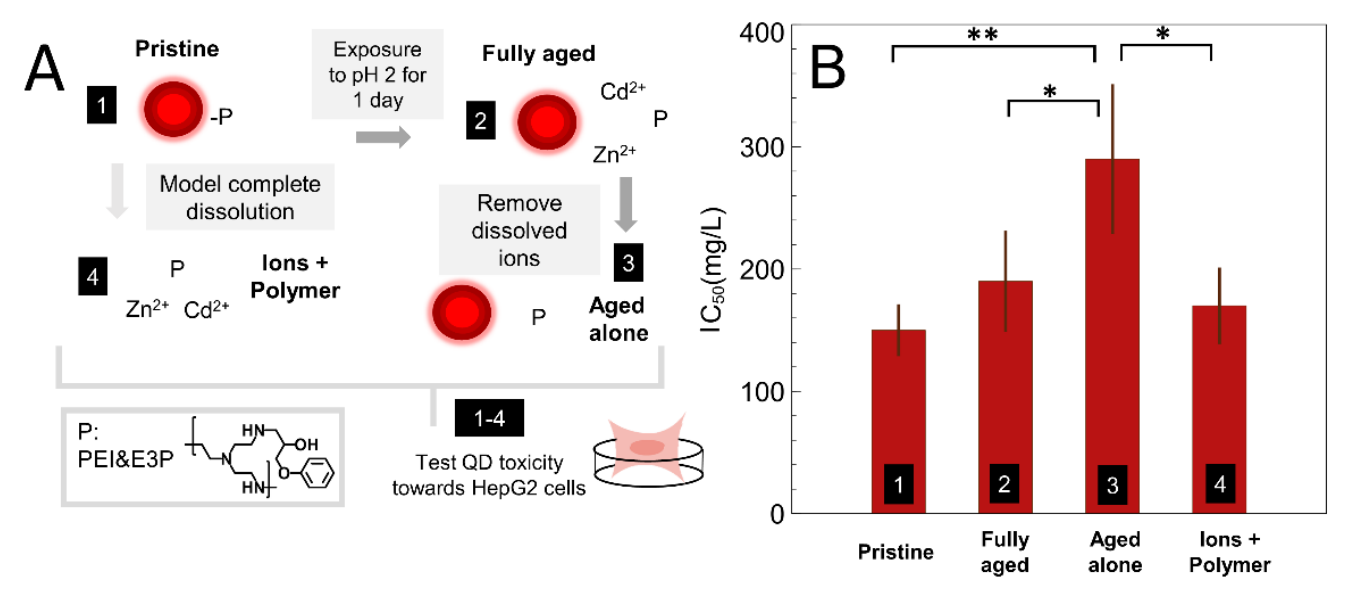

Figure 5: Ageing of CdSe/ZnS-PEI\&E3P reduces toxicity in human liver cells. (A) Models used to test for impact of ageing on QD toxicity. (B) Comparison of IC $_{50}$ values of pristine QDs with aged QD models in HepG2 cells. Each value is the mean and standard deviation from three biological experiments. $*=p<0.05 * *=p<0.01$.

Our findings support our hypothesis that leached components, including $\mathrm{Cd}^{2+}$ and PEI\&E3P, and less so $\mathrm{Zn}^{2+}$ are a major source of toxicity. Importantly, because these components are leached from QDs upon environmental weathering, the remaining aged QD particles are significantly less toxic compared to these components and pristine QDs. Additionally, the aged CdSe/ZnSPEI\&E3P could be more aggregated or have a different colloidal stability in media than pristine QDs. Whether the $\mathrm{Cd}^{2+}, \mathrm{Zn}^{2+}$, PEI\&E3P, or QDs will pose a significant risk to humans depends on mainly two factors: relevant doses and physiological conditions. In terms of relevant dose, further studies are needed to determine the possible amounts of QDs that will leak out from damaged electronic displays. Once determined, the amount of QDs that could have contact with liver cells also needs to be investigated. Finally, different physiological conditions such as 
bloodstream conditions or gastric conditions can also possibly alter the QDs cytotoxicity via changing its structural stability and biological solubility.

\section{Conclusions:}

CdSe/ZnS-PEI\&E3P were synthesized with a commercially-relevant capping polymer to close the knowledge gap between products embedded with QDs and model QDs with small mobile ligands. Dissolution results indicated that the CdSe core of CdSe/ZnS-PEI\&E3P does not dissolve at circumneutral $\mathrm{pH}$, even after 6 months. At low pH, dissolution of the CdSe core is temporarily hindered by the presence of $\mathrm{ZnS}$ and CdS shells (75\% decrease in Cd dissolution after 1 day compared to unshelled CdSe). The presence of oxygen in the dark did not facilitate the dissolution of the QD. Aggregation of the QDs in solution was documented at $\mathrm{pH}$ 4, forming loose (after 24h) and eventually dense $\sim 100 \mathrm{~nm}$ aggregates (after 6 months). These relatively robust QDs can serve as a platform to further investigate QDs from display applications because of their limited dissolution and complex coating.

Interestingly, QDs exposed to an environmentally relevant conditions are significantly less toxic compared to intact pristine QDs ( $\mathrm{IC}_{50}$ of 150 and $290 \mathrm{mg} / \mathrm{L}$, respectively). Our results suggest that this reduction in toxicity to human cells is a result of the lower concentration of toxic components, $\mathrm{Cd}^{2+}$ and $\mathrm{Zn}^{2+}$ available following their dissolution (10\% and $100 \%$ present as ions, respectively). As such, QDs that are left in the environment for long periods (6 months) will likely release higher concentrations of toxic ions and polymer components, thus the surrounding aqueous phase could result in more serious toxicological effects whereas the QD itself would have diminished toxicity.

In conclusion, this paper highlights the need for studies on the environmental implications of industrially relevant QDs to investigate the complex interactions with capping polymers. 


\section{METHODS:}

\section{Synthesis of CdSe/ZnS QDs:}

The synthesis of the CdSe quantum dots was based on the methods utilized by J. Zhou et al. and

R. Xie et al. (see SI for step-by-step procedure and modifications). ${ }^{26,27}$ The synthesis produced $\mathrm{CdSe} / \mathrm{CdS} / \mathrm{Cd}_{0.5} \mathrm{Zn}_{0.5} \mathrm{~S} / \mathrm{ZnS}$ QDs with octadecylamine ligands, which will be referred to as CdSe/ZnS.

\section{Octadecylamine and PEI \& E3P Ligand Exchange:}

Branched polyethyleneimine (PEI) as a 50\% w/w solution and 1,3-epoxy-3phenoxypropane were purchased from Sigma Aldrich. Before use, the PEI solution was frozen and lyophilized overnight to remove the water content (checked with ${ }^{1} \mathrm{H}-\mathrm{NMR}$, see SI).

To synthesize the polymer, $0.300 \mathrm{~g}$ of PEI was added to a two-neck $25 \mathrm{~mL}$ round bottom flask. The flask was set up under a reflux system and heated to $100^{\circ} \mathrm{C} . \mathrm{N}_{2}$ was flushed through the system so that no air was present during the reaction. The 1,2-epoxy-3-phenoxypropane (E3P) precursor was prepared by adding $0.150 \mathrm{~g}$ of E3P into a 0.5 Dram vial. Once the reaction flask reached $100^{\circ} \mathrm{C}$, the E3P precursor was injected into the solution, and the monomers were left to react for 30 min under nitrogen and stirring at $200 \mathrm{rpm}$.

To add the capping polymer on the surface of the nanoparticles, $20 \mathrm{mg}$ of the previously prepared, shelled quantum dots was dissolved in $2 \mathrm{~mL}$ of toluene. After the polymer synthesis was conducted for 30 minutes, the quantum dot solution was injected directly into the reaction flask. The solution was left stirring under $\mathrm{N}_{2}$ for an additional $30 \mathrm{~min}$. Once the ligand exchange was completed, the solution was cooled to room temperature, while the precipitate settled to the bottom 
of the flask. The excess toluene was removed using a rotary evaporator and the product was dried in a vacuum oven at $<50^{\circ} \mathrm{C}$ overnight. The final dried product was stored in a desiccator.

\section{Dissolution Tests}

CdSe/ZnS-PEI\&E3P was added to solutions of different $\mathrm{pH}$ at the same concentration (150 mg/L). We had previously confirmed none of the Cd and Zn were present as ions in this initial solution (see Table S2). The $\mathrm{pH}$ of solutions was adjusted with acetic acid to be either 2, 4, 6, or 8. Once the QD-containing solutions in glass vials were prepared, they were left to sit for 24h or 6 months in the dark while stirring at $100 \mathrm{rpm}$ at ambient lab temperature $\left(20-22{ }^{\circ} \mathrm{C}\right)$. Then each of these solutions was passed through a 3 KDa Amicon Ultra-4 Centrifugal Filter Unit for 45 minutes at 4500 rpm (Sorvall Legend XF).

The method used to separate intact QDs from dissolved ions relied on the use of 3 KDa centrifugal filters (see SI for details). The retentate was recovered from the filter by adding $1 \mathrm{~mL}$ of $30 \% \mathrm{H}_{2} \mathrm{O}_{2}$. After $10 \mathrm{~min}$, this solution was pipetted into a digestion tube and heated for 30 minutes at $95^{\circ} \mathrm{C}$. Twenty minutes into this digestion, $1 \mathrm{~mL}$ of $70 \%$ nitric acid (Trace metal grade) was added to the retentate. At the end of the thirty minutes of the $\mathrm{H}_{2} \mathrm{O}_{2}$ digestion, the $1 \mathrm{~mL}$ of nitric acid from the retentate was added to the $\mathrm{H}_{2} \mathrm{O}_{2}$ - containing solution. Then this solution was heated to $95^{\circ} \mathrm{C}$ for 60 minutes to complete the digestion. The solution was then diluted to $15 \mathrm{~mL}$ with deionized water and measured in the ICP-OES (see SI for conditions).

The filtrate was divided into two aliquots of $1.5 \mathrm{~mL}$ into digestion tubes and digested with a similar procedure. First, $1 \mathrm{~mL}$ of hydrogen peroxide was added and heated to $95^{\circ} \mathrm{C}$ for 30 minutes. Second, nitric acid was added to the solutions and heated to $95^{\circ} \mathrm{C}$ for 30 minutes. The solution was then diluted to $15 \mathrm{~mL}$ with deionized water and measured in the ICP-OES.

\section{Cell culture and quantum dot model components:}


HepG2 cells (ATCC ${ }^{\circledR}$ HB-8065) were cultured at $37{ }^{\circ} \mathrm{C}$ with $5 \% \mathrm{CO}_{2}$ in Dulbecco's modified Eagle's media (DMEM) with phenol red (Gibco) supplemented with 10\% (v/v) fetal bovine serum (Gibco) and 1\% (v/v) antibiotics/antimycotics (Gibco). Cells were maintained in $10 \mathrm{~cm}$ petri dishes and passaged using $0.25 \%$ (w/v) Trypsin- 0.53 mM EDTA prior to reaching 70-80\% confluency.

All individual QD components and QD model systems were prepared immediately prior to use. Individual QD components for testing including Cadmium chloride (Sigma), Cadmium nitrate tetrahydrate (Sigma), Zinc sulfate heptahydrate (Sigma), Zinc acetate (Sigma), and PEI\&E3P (synthesized according to Scheme 1) were suspended in the supplemented DMEM. All QD models were prepared individually as stock solutions in supplemented DMEM at $2 \mathrm{~g} / \mathrm{L}$. Specifically, the pristine QD model was synthesized as described in 'QD synthesis' section and the 24h-aged model was synthesized and aged as described above in section 'Dissolution Tests'. A QD model called "ions and capping polymer" was prepared with $\mathrm{Cd}^{2+}$ and $\mathrm{Zn}^{2+}$ ions as well as the PEI\&E3P ligand representing the total dissolved components from $2 \mathrm{~g} / \mathrm{L}$ of 24-h aged QDs as described in Figure 2. Finally, the full aged QD model was prepared by combining the $2 \mathrm{~g} / \mathrm{L} 24 \mathrm{~h}$-aged and filtered QDs with the total dissolved components.

\section{In vitro cell viability assay:}

For each assay, HepG2 cells were seeded in a clear 96-well microplate at a density of 6000 cells/well and incubated for $24 \mathrm{~h}$. The media was then carefully replaced with serial dilutions of the QD components or QD model solution and incubated for 24h. Cell viability was then assessed using the CellTiter-Glo® luminescence assay (Promega) as per manufacturer instructions. Specifically, the CellTiter-Glo reagent was added to each well, gently mixed for 2 min and incubated in the dark for 10 minutes at room temperature. $80 \mu \mathrm{L}$ of the mixture from each well was transfer to a white 96-well plate and measured on a Spark ${ }^{\circledR}$ multimode plate reader (Tecan 
Life Sciences). Luminescence was recorded at $25^{\circ} \mathrm{C}$ (Attenuation automatic, integration time 1000 ms). Cell viability was plotted as the mean and standard deviation of relative luminescence units (RLU). IC 50 $_{50}$ values were derived using nonlinear regression (Inhibitor vs. response - Variable slope four parameters) using GraphPad Prism (GraphPad Software, Inc., La Jolla, CA, USA). Statistical comparisons were performed using a one-way ANOVA followed by Tukey's multiple comparisons test.

\section{Characterization instruments and methods:}

The formation of CdSe and CdSe/ZnS nanoparticles was monitored by measuring their photoluminescence and UV-Vis spectra using a Cary Eclipse Fluorescence Spectrophotometer and a Jasco V-670 Spectrophotometer, respectively. To prepare for the measurements, the CdSe cores were suspended in toluene, and the shelled CdSe/ZnS nanoparticles and monolayer aliquots were suspended in hexanes. The excitation wavelength was set at $400 \mathrm{~nm}$ when conducting the fluorescence measurements. The spectrum was taken over a range of $425-775 \mathrm{~nm}$. The UV-Vis spectrophotometer was set at a scanning rate of $200 \mathrm{~nm} / \mathrm{min}$, and the spectrum was taken over a range of $400-800 \mathrm{~nm}$.

Transmission Electron Microscopy (TEM) was done with an FEI Technai G² F20 200 kV CryoSTEM to visualize the nanoparticles. Samples were deposited onto a Cu grid with carbon backing (from Electron Microscopy Sciences).

PerkinElmer Optima 8300 ICP-OES was used to measure $\mathrm{Zn}$ and $\mathrm{Cd}$ concentrations at wavelengths $206.20 \mathrm{~nm}$ and $228.80 \mathrm{~nm}$, respectively.

Bruker D8 Advantage X-Ray Diffractometer using a Cu-Ka $(\lambda=1.5418 \AA ̊)$ source acquired pXRD spectra. The instrument operated at $30 \mathrm{kV}$ and $10 \mathrm{~mA}$ and was equipped with a LinxEye detector and a Ni filter. 
${ }^{1} \mathrm{H}-\mathrm{NMR}$ samples were prepared by dispersing $1 \mathrm{mg}$ of samples into $0.5 \mathrm{~mL}$ of deuterated chloroform. Samples were run on Bruker AVIIIHD 500 MHz NMR spectrometer.

\section{AUTHOR INFORMATION}

\section{Corresponding Authors}

Audrey Moores; orcid.org/0000-0003-1259-913X; Email: audrey.moores@mcgill.ca

Subhasis Ghoshal; orcid.org/0000-0001-9968-6150; Email: subhasis.ghoshal@mcgill.ca

Maureen McKeague; orcid.org/0000-0002-3750-6027; Email: maureen.mckeague@mcgill.ca

\section{Author Contributions}

The manuscript was written through the contributions of all authors. All authors have approved the final version of the manuscript.

\section{Funding Sources}

We thank the Natural Science and Engineering Research Council of Canada (NSERC) Discovery Grant and Discovery Accelerator Supplement, the Canada Foundation for Innovation (CFI), the McGill Sustainability Systems Initiative (MSSI), the Fonds de Recherche du Québec -

Nature et Technologies (FRQNT) Graduate Scholarship program (AB) and Centre for Green Chemistry and Catalysis (CGCC), the Canada Research Chair Program, and McGill University for their financial support.

\section{ACKNOWLEDGMENT}


We thank the Facility for Electron Microscopy Research (FEMR) of McGill University for help in acquiring electron microscope data, specifically David Liu and Kelly Sears. We thank Robin Stein, Hatem Titi and Petr Fiurasek at the MC2 facility at McGill University for help in acquiring NMR, XRD, and TGA data. We thank Arshath Abdul Rahim for training and help acquiring ICPOES data. We thank Andrew Golsztajn in the McGill Chemical Engineering Department analytical laboratory for his help in digesting TV films and measuring them with another ICP-OES.

\section{ASSOCIATED CONTENT}

Supporting Information. The following files are available free of charge.

Analysis of the display film, synthesis and analysis of quantum dots, validations of dissolution tests, DLS measurements and methods, and cell viability curves from which $\mathrm{IC}_{50}$ values were derived. (PDF)

\section{REFERENCES:}

(1) Pan, Z.; Rao, H.; Mora-Seró, I.; Bisquert, J.; Zhong, X. Quantum Dot-Sensitized Solar Cells. Chem. Soc. Rev. 2018, 47 (20), 7659-7702. https://doi.org/10.1039/C8CS00431E.

(2) Filali, S.; Pirot, F.; Miossec, P. Biological Applications and Toxicity Minimization of Semiconductor Quantum Dots. Trends Biotechnol. 2020, 38 (2), 163-177. https://doi.org/10.1016/j.tibtech.2019.07.013.

(3) Hanifi, D. A.; Bronstein, N. D.; Koscher, B. A.; Nett, Z.; Swabeck, J. K.; Takano, K.; Schwartzberg, A. M.; Maserati, L.; Vandewal, K.; Burgt, Y. van de; Salleo, A.; Alivisatos, A. P. Redefining Near-Unity Luminescence in Quantum Dots with Photothermal Threshold Quantum Yield. Science 2019, 363 (6432), 1199-1202. https://doi.org/10.1126/science.aat3803.

(4) McCoy, M. A Quantum Leap In Display Quality From Quantum Dots https://cen.acs.org/articles/odsmeter.html (accessed 2019 -08 -28). 
(5) Nanosys. Nanosys on track for record shipments of Quantum Dots for displays in 2019 https://www.prnewswire.com/news-releases/nanosys-on-track-for-record-shipments-ofquantum-dots-for-displays-in-2019-300937397.html (accessed 2020 -01 -29).

(6) Zhu, R.; Luo, Z.; Chen, H.; Dong, Y.; Wu, S.-T. Realizing Rec. 2020 Color Gamut with Quantum Dot Displays. Opt. Express 2015, 23 (18), 23680-23693. https://doi.org/10.1364/OE.23.023680.

(7) Bodnarchuk, M. I.; Kovalenko, M. V. Engineering Colloidal Quantum Dots. In Colloidal Quantum Dot Optoelectronics and Photovoltaics; Konstantatos, G., Sargent, E. H., Eds.; Cambridge University Press: Cambridge, 2013; pp 1-29. https://doi.org/10.1017/CBO9781139022750.002.

(8) Rzigalinski, B. A.; Strobl, J. S. Cadmium-Containing Nanoparticles: Perspectives on Pharmacology and Toxicology of Quantum Dots. Toxicol. Appl. Pharmacol. 2009, 238 (3), 280-288. https://doi.org/10.1016/j.taap.2009.04.010.

(9) Dubrow, R. S.; Freeman, W. P.; Lee, E.; Furuta, P. Quantum Dot Films, Lighting Devices, and Lighting Methods. US9199842B2, December 1, 2015.

(10) McBride, J.; Treadway, J.; Feldman, L. C.; Pennycook, S. J.; Rosenthal, S. J. Structural Basis for Near Unity Quantum Yield Core/Shell Nanostructures. Nano Lett. 2006, 6 (7), 1496-1501. https://doi.org/10.1021/nl060993k.

(11) Gerion, D.; Pinaud, F.; Williams, S. C.; Parak, W. J.; Zanchet, D.; Weiss, S.; Alivisatos, A. P. Synthesis and Properties of Biocompatible Water-Soluble Silica-Coated CdSe/ZnS Semiconductor Quantum Dots ${ }^{\dagger}$. J. Phys. Chem. B 2001, 105 (37), 8861-8871. https://doi.org/10.1021/jp0105488.

(12) Dubois, F.; Mahler, B.; Dubertret, B.; Doris, E.; Mioskowski, C. A Versatile Strategy for Quantum Dot Ligand Exchange. J. Am. Chem. Soc. 2007, 129 (3), 482-483. https://doi.org/10.1021/ja067742y.

(13) Balde, C. P.; Forti, V.; Gray, V.; Kuehr, R.; Stegmann, P. The Global E-Waste Monitor 2017; United Nations University (UNU), International Telecommunication Union (ITU) \& International Solid Waste Association (ISWA), Bonn/Geneva/Vienne, 2017; pp 1-116.

(14) Fawell, J. Cadmium in Drinking-Water; Background document for development of WHO Guidelines for Drinking-water Quality; WHO/SDE/WSH/03.04/80/Rev/1; World Health Organization: Geneva, 2011; pp 1-16.

(15) Nowack, B.; Mitrano, D. M. Procedures for the Production and Use of Synthetically Aged and Product Released Nanomaterials for Further Environmental and Ecotoxicity Testing. NanoImpact 2018, 10, 70-80. https://doi.org/10.1016/j.impact.2017.12.001.

(16) Paydary, P.; Larese-Casanova, P. Water Chemistry Influences on Long-Term Dissolution Kinetics of CdSe/ZnS Quantum Dots. J. Environ. Sci. 2020, 90, 216-233. https://doi.org/10.1016/j.jes.2019.11.011.

(17) Supiandi, N. I.; Charron, G.; Tharaud, M.; Benedetti, M. F.; Sivry, Y. Tracing MultiIsotopically Labelled CdSe/ZnS Quantum Dots in Biological Media. Sci. Rep. 2020, 10 (1), 2866. https://doi.org/10.1038/s41598-020-59206-w.

(18) Wiecinski, P. N.; Metz, K. M.; King Heiden, T. C.; Louis, K. M.; Mangham, A. N.; Hamers, R. J.; Heideman, W.; Peterson, R. E.; Pedersen, J. A. Toxicity of Oxidatively Degraded Quantum Dots to Developing Zebrafish (Danio Rerio). Environ. Sci. Technol. 2013, 47 (16), 9132-9139. https://doi.org/10.1021/es304987r. 
(19) Mahendra, S.; Zhu, H.; Colvin, V. L.; Alvarez, P. J. Quantum Dot Weathering Results in Microbial Toxicity. Environ. Sci. Technol. 2008, 42 (24), 9424-9430. https://doi.org/10.1021/es8023385.

(20) Xiao, Y.; Ho, K. T.; Burgess, R. M.; Cashman, M. Aggregation, Sedimentation, Dissolution, and Bioavailability of Quantum Dots in Estuarine Systems. Environ. Sci. Technol. 2017, 51 (3), 1357-1363. https://doi.org/10.1021/acs.est.6b04475.

(21) Carboni, A.; Gelabert, A.; Charron, G.; Faucher, S.; Lespes, G.; Sivry, Y.; Benedetti, M. F. Mobility and Transformation of CdSe/ZnS Quantum Dots in Soil: Role of the Capping Ligands and Ageing Effect. Chemosphere 2020, 254, 126868. https://doi.org/10.1016/j.chemosphere.2020.126868.

(22) Liu, J.; Katahara, J.; Li, G.; Coe-Sullivan, S.; Hurt, R. H. Degradation Products from Consumer Nanocomposites: A Case Study on Quantum Dot Lighting. Environ. Sci. Technol. 2012, 46 (6), 3220-3227. https://doi.org/10.1021/es204430f.

(23) Brown, F. C.; Bi, Y.; Chopra, S. S.; Hristovski, K. D.; Westerhoff, P.; Theis, T. L. End-ofLife Heavy Metal Releases from Photovoltaic Panels and Quantum Dot Films: Hazardous Waste Concerns or Not? ACS Sustain. Chem. Eng. 2018, 6 (7), 9369-9374. https://doi.org/10.1021/acssuschemeng.8b01705.

(24) Oh, E.; Liu, R.; Nel, A.; Gemill, K. B.; Bilal, M.; Cohen, Y.; Medintz, I. L. Meta-Analysis of Cellular Toxicity for Cadmium-Containing Quantum Dots. Nat. Nanotechnol. 2016, 11 (5), 479-486. https://doi.org/10.1038/nnano.2015.338.

(25) Talapin, D. V.; Mekis, I.; Götzinger, S.; Kornowski, A.; Benson, O.; Weller, H. $\mathrm{CdSe} / \mathrm{CdS} / \mathrm{ZnS}$ and $\mathrm{CdSe} / \mathrm{ZnSe} / \mathrm{ZnS}$ Core-Shell-Shell Nanocrystals. J. Phys. Chem. B 2004, 108 (49), 18826-18831. https://doi.org/10.1021/jp046481g.

(26) Zhou, J.; Zhu, M.; Meng, R.; Qin, H.; Peng, X. Ideal CdSe/CdS Core/Shell Nanocrystals Enabled by Entropic Ligands and Their Core Size-, Shell Thickness-, and LigandDependent Photoluminescence Properties. J. Am. Chem. Soc. 2017, 139 (46), 16556-16567. https://doi.org/10.1021/jacs.7b07434.

(27) Xie, R.; Kolb, U.; Li, J.; Basché, T.; Mews, A. Synthesis and Characterization of Highly Luminescent $\mathrm{CdSe}-$ Core $\mathrm{CdS} / \mathrm{Zn}{ }_{0.5} \mathrm{Cd}{ }_{0.5} \mathrm{~S} / \mathrm{ZnS}$ Multishell Nanocrystals. J. Am. Chem. Soc. 2005, 127 (20), 7480-7488. https://doi.org/10.1021/ja042939g.

(28) Supiandi, N. I.; Charron, G.; Tharaud, M.; Cordier, L.; Guigner, J.-M.; Benedetti, M. F.; Sivry, Y. Isotopically Labeled Nanoparticles at Relevant Concentrations: How Low Can We Go? The Case of CdSe/ZnS QDs in Surface Waters. Environ. Sci. Technol. 2019, 53 (5), 2586-2594. https://doi.org/10.1021/acs.est.8b04096.

(29) Durisic, N.; Godin, A. G.; Walters, D.; Grütter, P.; Wiseman, P. W.; Heyes, C. D. Probing the "Dark" Fraction of Core-Shell Quantum Dots by Ensemble and Single Particle PHDependent Spectroscopy. ACS Nano 2011, 5 (11), 9062-9073. https://doi.org/10.1021/nn203272p.

(30) Wang, W.; Germanenko, I.; El-Shall, M. S. Room-Temperature Synthesis and Characterization of Nanocrystalline CdS, ZnS, and CdxZn1-XS. Chem. Mater. 2002, 14 (7), 3028-3033. https://doi.org/10.1021/cm020040x.

(31) Surana, K.; Salisu, I. T.; Mehra, R. M.; Bhattacharya, B. A Simple Synthesis Route of Low Temperature CdSe-CdS Core-Shell Quantum Dots and Its Application in Solar Cell. Opt. Mater. 2018, 82, 135-140. https://doi.org/10.1016/j.optmat.2018.05.060.

(32) S. Chopra, S.; Bi, Y.; C. Brown, F.; L. Theis, T.; D. Hristovski, K.; Westerhoff, P. Interdisciplinary Collaborations to Address the Uncertainty Problem in Life Cycle 
Assessment of Nano-Enabled Products: Case of the Quantum Dot-Enabled Display. Environ. Sci. Nano 2019, 6 (11), 3256-3267. https://doi.org/10.1039/C9EN00603F.

(33) Yu, W. W.; Peng, X. Formation of High-Quality CdS and Other II-VI Semiconductor Nanocrystals in Noncoordinating Solvents: Tunable Reactivity of Monomers. Angew. Chem. Int. Ed. 2002, 41 (13), 2368-2371. https://doi.org/10.1002/15213773(20020703)41:13<2368::AID-ANIE2368>3.0.CO;2-G.

(34) US EPA, O. SW-846 Test Method 1311: Toxicity Characteristic Leaching Procedure https://www.epa.gov/hw-sw846/sw-846-test-method-1311-toxicity-characteristicleaching-procedure (accessed 2019 -07 -12).

(35) Gray, P. J.; Hornick, J. E.; Sharma, A.; Weiner, R. G.; Koontz, J. L.; Duncan, T. V. Influence of Different Acids on the Transport of CdSe Quantum Dots from Polymer Nanocomposites to Food Simulants. Environ. Sci. Technol. 2018, 52 (16), 9468-9477. https://doi.org/10.1021/acs.est.8b02585.

(36) Seow, W. Y.; Liang, K.; Kurisawa, M.; Hauser, C. A. E. Oxidation as a Facile Strategy To Reduce the Surface Charge and Toxicity of Polyethyleneimine Gene Carriers. Biomacromolecules 2013, 14 (7), 2340-2346. https://doi.org/10.1021/bm4004628.

(37) Aldana, J.; Wang, Y. A.; Peng, X. Photochemical Instability of CdSe Nanocrystals Coated by Hydrophilic Thiols. J. Am. Chem. Soc. 2001, 123 (36), 8844-8850. https://doi.org/10.1021/ja016424q.

(38) Li, Y.; Zhang, W.; Li, K.; Yao, Y.; Niu, J.; Chen, Y. Oxidative Dissolution of PolymerCoated CdSe/ZnS Quantum Dots under UV Irradiation: Mechanisms and Kinetics. Environ. Pollut. 2012, 164, 259-266. https://doi.org/10.1016/j.envpol.2012.01.047.

(39) Hsieh, Y. H.; Huang, C. P. Photooxidative Dissolution of CdS(s) Part I. Important Factors and Mechanistic Aspects. Colloids Surf. 1991, 53 (2), 275-295. https://doi.org/10.1016/0166-6622(91)80142-B.

(40) Schippers, A. Biogeochemistry of Metal Sulfide Oxidation in Mining Environments, Sediments, and Soils. In Sulfur Biogeochemistry - Past and Present; Geological Society of America, 2004. https://doi.org/10.1130/0-8137-2379-5.49.

(41) Wilmot, P. D.; Cadee, K.; Katinic, J. J.; Kavanagh, B. V. Kinetics of Sulfide Oxidation by Dissolved Oxygen. J. Water Pollut. Control Fed. 1988, 60 (7), 1264-1270.

(42) Eskelsen, J. R.; Xu, J.; Chiu, M.; Moon, J.-W.; Wilkins, B.; Graham, D. E.; Gu, B.; Pierce, E. M. Influence of Structural Defects on Biomineralized ZnS Nanoparticle Dissolution: An in-Situ Electron Microscopy Study. Environ. Sci. Technol. 2018, 52 (3), 1139-1149. https://doi.org/10.1021/acs.est.7b04343.

(43) Li, C.; Hassan, A.; Palmai, M.; Snee, P. T.; Baveye, P. C.; Darnault, C. J. G. Colloidal Stability and Aggregation Kinetics of Nanocrystal CdSe/ZnS Quantum Dots in Aqueous Systems: Effects of PH and Organic Ligands. J. Nanoparticle Res. 2020, 22 (11), 349. https://doi.org/10.1007/s11051-020-05080-6.

(44) Green, M. The Nature of Quantum Dot Capping Ligands. J. Mater. Chem. 2010, 20 (28), 5797-5809. https://doi.org/10.1039/C0JM00007H.

(45) Chakraborty, D.; Ethiraj, K. R.; Chandrasekaran, N.; Mukherjee, A. Mitigating the Toxic Effects of CdSe Quantum Dots towards Freshwater Alga Scenedesmus Obliquus: Role of

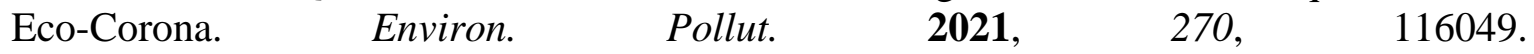
https://doi.org/10.1016/j.envpol.2020.116049.

(46) Marşan, D.; Şengül, H.; Özdil, A. M. A. Comparative Assessment of the Phase Transfer Behaviour of InP/ZnS and CuInS/ZnS Quantum Dots and CdSe/ZnS Quantum Dots under 
Varying Environmental Conditions. Environ. Sci. Nano 2019, 6 (3), 879-891. https://doi.org/10.1039/C8EN01073K.

(47) Noh, M.; Kim, T.; Lee, H.; Kim, C.-K.; Joo, S.-W.; Lee, K. Fluorescence Quenching Caused by Aggregation of Water-Soluble CdSe Quantum Dots. Colloids Surf. Physicochem. Eng. Asp. 2010, 359 (1), 39-44. https://doi.org/10.1016/j.colsurfa.2010.01.059.

(48) Metz, K. M.; Mangham, A. N.; Bierman, M. J.; Jin, S.; Hamers, R. J.; Pedersen, J. A. Engineered Nanomaterial Transformation under Oxidative Environmental Conditions: Development of an in Vitro Biomimetic Assay. Environ. Sci. Technol. 2009, 43 (5), 15981604. https://doi.org/10.1021/es802217y.

(49) Tarantini, A.; Wegner, K. D.; Dussert, F.; Sarret, G.; Beal, D.; Mattera, L.; Lincheneau, C.; Proux, O.; Truffier-Boutry, D.; Moriscot, C.; Gallet, B.; Jouneau, P.-H.; Reiss, P.; Carrière, M. Physicochemical Alterations and Toxicity of InP Alloyed Quantum Dots Aged in Environmental Conditions: A Safer by Design Evaluation. NanoImpact 2019, 14, 100168. https://doi.org/10.1016/j.impact.2019.100168.

(50) Sturgill, M. G.; Lambert, G. H. Xenobiotic-Induced Hepatotoxicity: Mechanisms of Liver Injury and Methods of Monitoring Hepatic Function. Clin. Chem. 1997, 43 (8), 1512-1526. https://doi.org/10.1093/clinchem/43.8.1512.

(51) Yong, K.-T.; Law, W.-C.; Hu, R.; Ye, L.; Liu, L.; Swihart, M. T.; Prasad, P. N. Nanotoxicity Assessment of Quantum Dots: From Cellular to Primate Studies. Chem. Soc. Rev. 2013, 42 (3), 1236-1250. https://doi.org/10.1039/C2CS35392J.

(52) Fotakis, G.; Timbrell, J. A. In Vitro Cytotoxicity Assays: Comparison of LDH, Neutral Red, MTT and Protein Assay in Hepatoma Cell Lines Following Exposure to Cadmium Chloride. Toxicol. Lett. 2006, 160 (2), 171-177. https://doi.org/10.1016/j.toxlet.2005.07.001.

(53) Lawal, A. O.; Ellis, E. Differential Sensitivity and Responsiveness of Three Human Cell Lines HepG2, 1321N1 and HEK 293 to Cadmium. J. Toxicol. Sci. 2010, 35 (4), 465-478. https://doi.org/10.2131/jts.35.465.

(54) Tang, S.; Allagadda, V.; Chibli, H.; Nadeau, J. L.; Mayer, G. D. Comparison of Cytotoxicity and Expression of Metal Regulatory Genes in Zebrafish (Danio Rerio) Liver Cells Exposed to Cadmium Sulfate, Zinc Sulfate and Quantum Dots. Metallomics 2013, 5 (10), 1411-1422.

(55) Mano, S. S.; Kanehira, K.; Sonezaki, S.; Taniguchi, A. Effect of Polyethylene Glycol Modification of TiO2 Nanoparticles on Cytotoxicity and Gene Expressions in Human Cell Lines. Int. J. Mol. Sci. 2012, 13 (3), 3703-3717. https://doi.org/10.3390/ijms13033703.

(56) Zheng, H.; Mortensen, L. J.; DeLouise, L. A. Thiol Antioxidant-Functionalized CdSe/ZnS Quantum Dots: Synthesis, Characterization, Cytotoxicity. J. Biomed. Nanotechnol. 2013, 9 (3), 382-392. https://doi.org/10.1166/jbn.2013.1561.

(57) Pathakoti, K.; Hwang, H.-M.; Xu, H.; Aguilar, Z. P.; Wang, A. In Vitro Cytotoxicity of CdSe/ZnS Quantum Dots with Different Surface Coatings to Human Keratinocytes HaCaT Cells. J. Environ. Sci. 2013, 25 (1), 163-171. https://doi.org/10.1016/S10010742(12)60015-1.

(58) Peng, L.; He, M.; Chen, B.; Wu, Q.; Zhang, Z.; Pang, D.; Zhu, Y.; Hu, B. Cellular Uptake, Elimination and Toxicity of CdSe/ZnS Quantum Dots in HepG2 Cells. Biomaterials 2013, 34 (37), 9545-9558. https://doi.org/10.1016/j.biomaterials.2013.08.038. 